\title{
Homozygosity and Heterozygosity for Null Col5a2 Alleles Produce Embryonic Lethality and a Novel Classic Ehlers-Danlos Syndrome-Related Phenotype

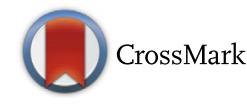

Arick C. Park, ${ }^{*}$ Charlotte L. Phillips, ${ }^{\dagger \dagger}$ Ferris M. Pfeiffer, ${ }^{\dagger \dagger}$ Drew A. Roenneburg, ${ }^{\S}$ John F. Kernien, ${ }^{*}$ Sheila M. Adams, Jeffrey M. Davidson," David E. Birk, and Daniel S. Greenspan*

From the Departments of Cell and Regenerative Biology* and Surgery, ${ }^{\S}$ University of Wisconsin, Madison, Wisconsin; the Departments of Biochemistry ${ }^{\dagger}$ and Orthopaedic Surgery, ${ }^{\ddagger}$ University of Missouri, Columbia, Missouri; the Department of Molecular Pharmacology and Physiology, "Morsani College of Medicine, University of South Florida, Tampa, Florida; and the Department of Pathology, Microbiology, and Immunology, "Vanderbilt University, Nashville, Tennessee

Accepted for publication March 17, 2015.

Address correspondence to Daniel S. Greenspan, Ph.D., Department of Cell and Regenerative Biology, School of Medicine and Public Health, University of Wisconsin, Room 4503 WIMRII, 1111 Highland Ave., Madison, WI 53705. E-mail: dsgreens@ wisc.edu.

\begin{abstract}
Null alleles for the COL5A1 gene and missense mutations for COL5A1 or the COL5A2 gene underlie cases of classic Ehlers-Danlos syndrome, characterized by fragile, hyperextensible skin and hypermobile joints. However, no classic Ehlers-Danlos syndrome case has yet been associated with COL5A2 null alleles, and phenotypes that might result from such alleles are unknown. We describe mice with null alleles for the Col5a2. Col5a2 $2^{-1-}$ homozygosity is embryonic lethal at approximately 12 days post conception. Unlike previously described mice null for Col5a1, which die at 10.5 days post conception and virtually lack collagen fibrils, Col5a2 $2^{-/-}$embryos have readily detectable collagen fibrils, thicker than in wild-type controls. Differences in $\mathrm{Col}_{5} a 2^{-/-}$and $\mathrm{Col} 5 \mathrm{a} 1^{-/-}$fibril formation and embryonic survival suggest that $\alpha 1(\mathrm{~V})_{3}$ homotrimers, a rare collagen $\mathrm{V}$ isoform that occurs in the absence of sufficient levels of $\alpha 2(\mathrm{~V})$ chains, serve functional roles that partially compensate for loss of the most common collagen $\mathrm{V}$ isoform. Col5a2 $2^{+/-}$adults have skin with marked hyperextensibility and reduced tensile strength at high strain but not at low strain. Col5a2 $2^{+/-}$adults also have aortas with increased compliance and reduced tensile strength. Results thus suggest that $\operatorname{COL} 5 A 2^{+/-}$humans, although unlikely to present with frank classic Ehlers-Danlos syndrome, are likely to have fragile connective tissues with increased susceptibility to trauma and certain chronic pathologic conditions. (Am J Pathol 2015, 185: 2000-2011; http://dx.doi.org/10.1016/j.ajpath.2015.03.022)
\end{abstract}

Collagen $\mathrm{V}$ is a low-abundance fibrillar collagen widely distributed in vertebrate tissues as $\alpha 1(\mathrm{~V})_{2} \alpha 2(\mathrm{~V})$ heterotrimers, ${ }_{1}$ which are incorporated into growing fibrils with the more abundant collagen I and involved in regulating the geometry and tensile strength of the resulting collagen $\mathrm{I} / \mathrm{V}$ heterotypic fibrils. ${ }^{2,3}$ Mutations in the genes encoding either the $\alpha 1(\mathrm{~V})^{4}$ or $\alpha 2(\mathrm{~V})^{5}$ chain can result in the human heritable connective tissue disorder classic Ehlers-Danlos syndrome (cEDS), clinical hallmarks of which include skin hyperextensibility, atrophic scarring, and joint hypermobility, with patients also often presenting with easy bruising and bleeding. ${ }^{6}$

At the molecular level, the collagen fibrils of cEDS skin have variability in diameter not seen in normal skin and include large diameter collagen fibril aggregates with abnormal cauliflower-like shapes when viewed in cross section. ${ }^{6}$ Deficits in the tensile strength of cEDS collagen fibrils are inferred from the hyperextensibility and fragility of cEDS skin and the hypermobility of cEDS joints.

Most cEDS cases that have been characterized at the molecular level are heterozygous for null alleles of the $\alpha 1(\mathrm{~V})$ chain gene $C O L 5 A 1,{ }^{7}$ resulting in the deposition of haploinsufficient levels of normal collagen $\mathrm{V}$ in tissues, with excess $\alpha 2(\mathrm{~V})$ chains unable to form stable triple helical molecules or be incorporated into the extracellular matrix $(\mathrm{ECM}){ }^{8}$

Supported by NIH grants AR044745 (D.E.B.), AR047746 (D.S.G.), and AI084853 (D.S.G.).

Disclosures: None declared. 


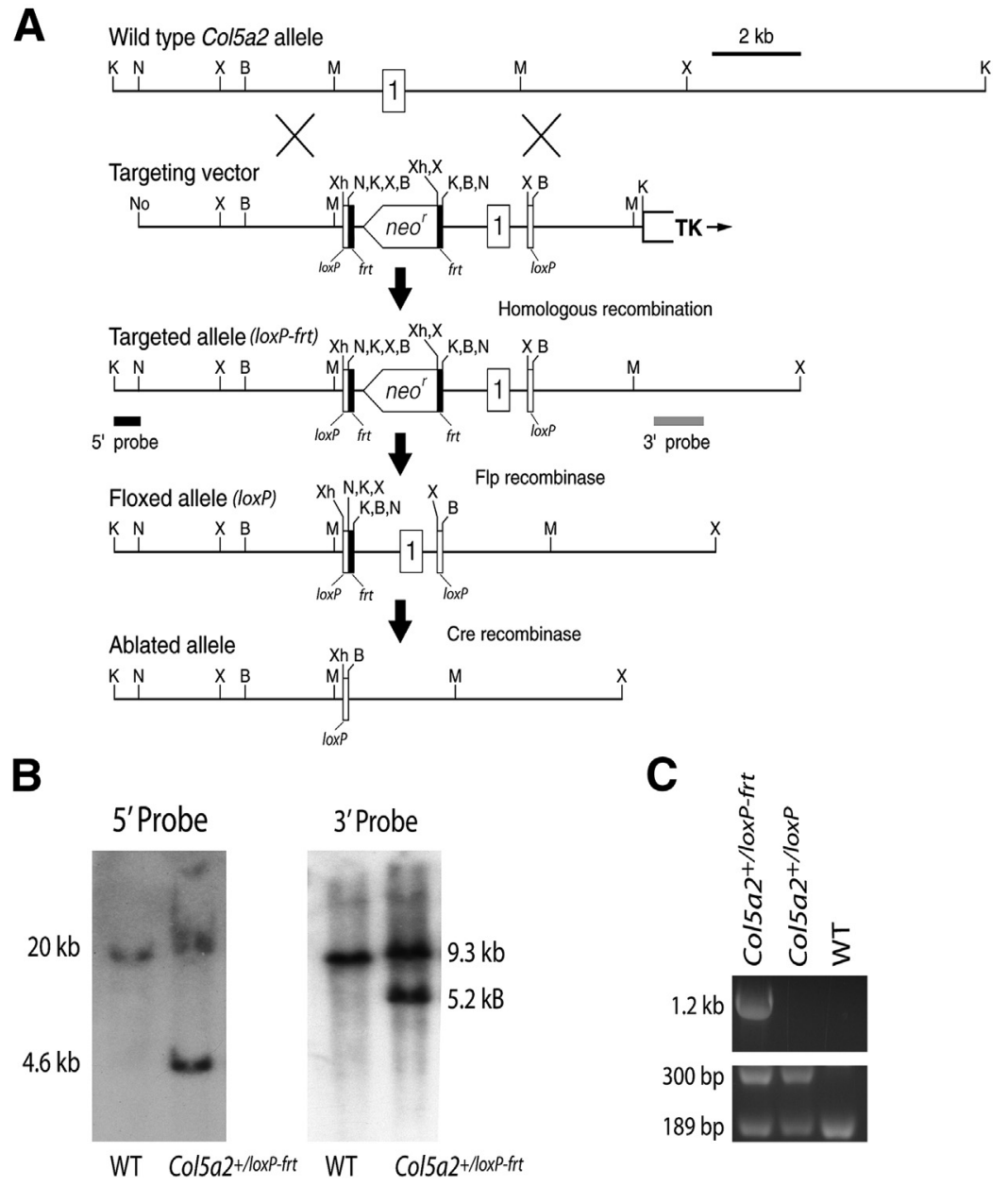

Figure 1 Conditional and constitutive disruption of Col5a2. A: Schematics are shown for the wild-type (WT) Col5a2 allele; targeting vector; correctly targeted Col5a $2^{\text {loxp-fit }}$ allele; floxed Col5a2 $2^{\text {loxp }}$ allele, in which the $n e{ }^{r}$ cassette has been excised via crossing with Flp deleter mice; and the ablated allele, in which Col5a2 sequences have been excised by Cre recombinase. Directionality is shown for transcription of $n e o^{r}$ and thymidine kinase cassettes. The box labeled 1 represents Col5a2 exon 1. frt and $\operatorname{lox} P$ sequences are represented by black and white vertical bars, respectively. Black and gray horizontal bars represent a 570-bp KpnI-NcoI Col5a2 fragment and an approximately $1200-\mathrm{kb}$ Col5a2 PCR amplicon, used as $5^{\prime}$ and $3^{\prime}$ external Southern blot probes, respectively. B: Southern blot analysis of KpnI- or XbaI-restricted genomic DNA from embryonic cell clones hybridized to the $5^{\prime}$ or $3^{\prime}$ probe, respectively. The $5^{\prime}$ probe detected approximately $20-\mathrm{kb}$ and $4.6-\mathrm{kb}$ bands for WT and targeted alleles, respectively, whereas the $3^{\prime}$ probe detected bands of 9.3and 5.2-kb from WT and targeted alleles, respectively. C: PCR genotyping of genomic DNA from mice heterozygous for the targeted Col5a $2^{\text {loxp-frt }}$ allele and from mice heterozygous for the $\operatorname{Col}_{2} a 2^{\text {loxP }}$ allele, from which the flrted $n e o^{r}$ cassette has been excised. Bands of $1.2 \mathrm{~kb}, 300 \mathrm{bp}$, and $189 \mathrm{bp}$ correspond to the Col5a2 ${ }^{\text {loxp-fit }}$ allele, Col5a2 ${ }^{\text {loxP }}$, and WT alleles, respectively. B, BamH1; $\mathrm{K}$, KpnI; M, MfeI; N, NcoI; No, NotI; X, XbaI; Xh, XhoI.

A lesser number of cEDS cases are associated with COL5AI missense mutations, and a number of these [eg, signal peptide and C-propeptide mutations that reduce secretion or incorporation of $\alpha 1(\mathrm{~V})$ chains into heterotrimers, respectively] may result in de facto functional haploinsufficiency rather than structurally abnormal collagen V in the ECM. ${ }^{7}$ An even smaller number of cEDS cases have been associated with missense mutations in the $\alpha 2(\mathrm{~V})$ chain gene COL5A2 and probably involve incorporation of aberrant collagen $1 / \mathrm{V}$ heterotypic fibrils, containing abnormal $\alpha 2(\mathrm{~V})$ chains, into the ECM. ${ }^{7}$ Interestingly, COL5A2 null alleles have yet to be detected in cEDS patients, leading to the suggestion that haploinsufficiency for the $\alpha 2(\mathrm{~V})$ chain may not lead to cEDS or, perhaps, to any clinically abnormal phenotype.

Previously, knockout of the $\alpha 1(\mathrm{~V})$ (Col5al) gene produced a mouse model in which $\mathrm{Col} \mathrm{al}^{+/-}$adults exhibit a skin phenotype similar to that of cEDS. ${ }^{9,10} \mathrm{Col}_{5} \mathrm{al}^{+/-}$ mice also have decreased aortic stiffness and tensile strength ${ }^{10}$ presumably corresponding to the easy bleeding and somewhat increased prevalence of aortic root dilation, thought to result from increased aortic compliance, in cEDS patients. ${ }^{11-13}$ The homozygous null Col5al ${ }^{-1-}$ phenotype is embryonic lethal at approximately embryonic day 10 , with a seeming absence of collagen fibril formation suggesting an early role for collagen $\mathrm{V}$ in a nucleation event necessary to collagen fibril formation. ${ }^{9}$ In another study, mice heterozygous for a small in-frame deletion in the N-telopeptide domain of the $\alpha 2(\mathrm{~V})$ chain were phenotypically normal, but homozygotes, which developed spinal abnormalities not characteristic of cEDS and most of which died before weaning, had skin with some features reminiscent of cEDS. ${ }^{14}$ A subsequent study on the same mice claimed the mutated allele to be functionally null. $^{15}$

We report the creation and characterization of mice with the first true null Col5a2 allele. Contrary to mice homozygous for the previously described Col5a2 mutant allele, ${ }^{14} \mathrm{Col}_{5} \mathrm{2}^{-/-}$ homozygous null mice are early embryonic lethal, consistent with the early embryonic lethality of the previously described $\mathrm{Colsal}^{-1-}$ mice. ${ }^{9}$ Differences in length of embryonic survival and in collagen fibril density and morphology between the Cols $\mathrm{C}^{-1-}$ embryos described here and the previously described $\mathrm{Col}_{5 \mathrm{al}}{ }^{-1-}$ mice $^{9}$ provide insights into the roles of different forms of collagen $\mathrm{V}$ in fibrillogenesis. Col5 $a 2^{+/-}$ adults have changes to the extensibility and tensile strength of skin and aortae. Implications of the data for $\alpha 2(\mathrm{~V})$ and collagen $\mathrm{V}$ function and for the possible phenotype of humans heterozygous null for COL5A2 are discussed. 


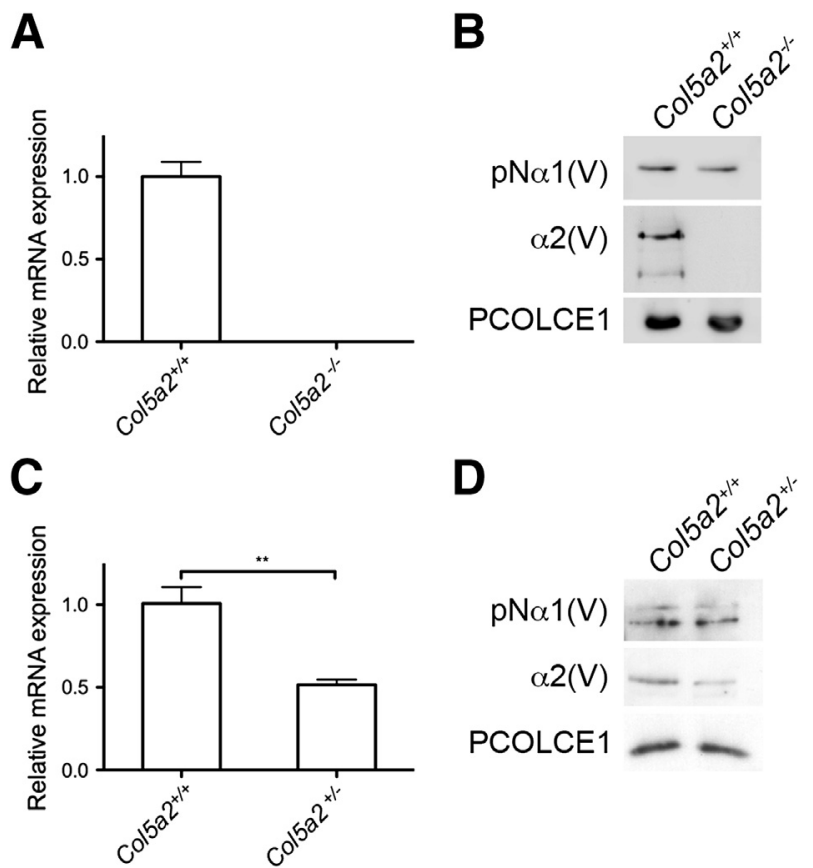

Figure 2 Real-time quantitative PCR (qPCR) and immunoblot comparisons of Col5a2 expression levels. A: qPCR of RNA from $\mathrm{Col}_{5 a 2^{+/+}}$and Col5a2 ${ }^{-/}$mouse embryonic fibroblasts (MEFs) consistently revealed essentially undetectable levels of Col5a2 mRNA transcript in Col5a2 ${ }^{-1-}$ MEFs, exhibiting large quantification cycle values outside the linear range of the primers. B: Immunoblotting was unable to detect $\alpha 2(\mathrm{~V})$ chains in the conditioned medium of Col5a2 ${ }^{-1-}$ MEFs. C: qPCR reveals Col5a2 RNA levels of $\mathrm{Col} 5 \mathrm{ar}^{+/-}$dermal fibroblasts to be half that of $\mathrm{Col} 5 a 2^{+/+}$dermal fibroblasts. D: Immunoblotting shows pro- $\alpha 2(\mathrm{~V})$ chain levels to be similarly reduced in the conditioned media of $\mathrm{Col} 5 \mathrm{a} 2^{+/-}$compared with levels found in conditioned $\mathrm{Col}_{5 \mathrm{a} 2^{+/+}}$dermal fibroblast medium. ${ }^{* *} P<0.01$.

\section{Materials and Methods}

Generation of Col5a2 $2^{\text {floxed/floxed }}$ and Col5a2-Null Mice

A block of sequence homology exists between the human COL5A2 and mouse Col5a2 genes surrounding the first exon, from nucleotide -157 (157 bp upstream of the major transcription start site of the human gene) to nucleotide +585 (330 bp into the first intron of COL5A2 and Col5a2), which contains a TATA box, putative Sp1 and NF-1 binding sites, a core enhancer motif, ${ }^{16}$ and two cis-acting elements shown by others to be essential to COL5A2 transcription. ${ }^{17,18}$ An additional homology block lies within a region corresponding to COL5A2 nucleotides -959 to -866 . Col5a2 genomic DNA, PCR amplified from a $129 / \mathrm{SvJ}$ genomic DNA library (Stratagene; Agilent Technologies, Santa Clara, CA), was inserted into the ploxPNT vector, ${ }^{19,20}$ such that the $5^{\prime} \operatorname{lox} P$ site of the vector is upstream of Col5a2 nucleotide -959 with an additional 3950 bp of genomic DNA upstream of that loxP site, to serve as the $5^{\prime}$ homology arm (Figure 1A). Downstream of the $3^{\prime} \operatorname{lox} P$ site of the ploxPNT vector is a $3^{\prime}$ homology arm that consists of the $5^{\prime}$-most $2160 \mathrm{bp}$ of the $60 \mathrm{~kb}$ Col5a 2 first intron. A neo ${ }^{r}$ cassette flanked with frt sites was inserted between the $3^{\prime}$ end of the 1544-bp promoter/first exon/first intron homology block and the downstream loxP site (Figure 1). The targeting vector also contains a thymidine kinase cassette for negative selection. The linearized targeting vector was electroporated into AB2.2 embryonic stem cells. Embryonic stem cell clones (480) doubly resistant to G418/gancyclovir were then expanded, and genomic DNA was isolated from 384 replica colonies and analyzed by Southern blot. Southern blots of XbaI- or KpnIrestricted genomic DNA from embryonic stem cell clones were hybridized to $3^{\prime}$ or $5^{\prime}$ external probes, respectively. The $3^{\prime}$ probe detected bands of 9.3 and $5.2 \mathrm{~kb}$ from wild-type and targeted alleles, respectively, whereas the $5^{\prime}$ probe detected approximately $20-\mathrm{kb}$ and $4.6-\mathrm{kb}$ bands for wild-type and targeted alleles, respectively (Figure 1B). Southern blotting with the $3^{\prime}$ probe identified 37 clones in which the banding pattern was consistent with correct targeting. Six of the clones were then expanded, and Southern blotting with $3^{\prime}$ and $5^{\prime}$ probes revealed the clones to be correctly targeted. Three of the clones, subjected to karyotyping, had correct karyotypes. Two of these clones were injected into blastocysts and implanted into foster mother mice. Chimeric progeny were then mated to wild-type C57BL/6 females, and resulting progeny, heterozygous for the targeted allele, were then crossed with the ACTB:FLPe transgenic line of Flp deleter mice, ${ }^{21}$ in which broad expression of enhanced thermal stability Flp recombinase, driven by the $\beta$-actin promoter, results in progeny in which the firted neo ${ }^{r}$ cassette has been deleted. Col5a $2^{+/ \text {floxed }}$ heterozygous progeny were then crossed for 10 generations onto a C57BL/6 background. To create mice with a constitutively null Col5a2 allele, heterozygous $\mathrm{Col} 5 \mathrm{a} 2^{\mathrm{flox} /+}$ mice were crossed with Myh11-cre, EGFP mice, ${ }^{22}$ which are known to express the transgene in germ cells (JAX Mice Database), resulting in progeny in which floxed Col5a2 sequences were universally deleted in all tissues. For genotyping, embryo yolk sacs and adult ear samples were digested in DirectPCR buffer (Viagen, Cedar Park, TX) with $0.8 \mathrm{mg} / \mathrm{mL}$ of proteinase K followed by PCR amplification with oligonucleotide primers $5^{\prime}$-GGTGATGGATGCTGACTTTG- $3^{\prime}$ and $5^{\prime}$-AGCTTCTGTGCGTGCCCTGG-3' (forward) and $5^{\prime}$-GGAGGGGAGGATAAAGAGCA-3'

Table 1 Phenotypes and Genotypes Observed During Gestation

\begin{tabular}{lrrrll}
\hline \multirow{2}{*}{$\begin{array}{l}\text { Days after } \\
\text { conception }\end{array}$} & $\begin{array}{l}\text { Total } \\
\text { embryos }\end{array}$ & \multicolumn{3}{c}{ Genotypes of all embryos } & \multirow{2}{*}{$\begin{array}{l}\text { Resorbed } \\
\text { (nongenotyped) }\end{array}$} \\
\cline { 3 - 5 } 10.5 & 44 & 9 & 25 & 10 & 0 \\
11.5 & 69 & 14 & 37 & $5(11)^{*}[2]^{\dagger}$ & 0 \\
12.5 & 19 & 6 & 13 & $(2)[2]$ & 0 \\
13.5 & 14 & 7 & 7 & $6^{\ddagger}$ & 0 \\
14.5 & 8 & 3 & 5 & 0 & 1 \\
15.5 & 10 & 2 & 6 & 0 & 2 \\
16.5 & 3 & 1 & 2 & 0 & 0 \\
17.5 & 35 & 6 & 29 & 0 & 0 \\
Weaning & 44 & 16 & 28 & 0 & \\
Total & 246 & & & & \\
\hline
\end{tabular}

*Parenthetical numbers indicate pronounced pallor and lack of heartbeat. ${ }^{\dagger}$ Bracketed numbers represent dead genotyped embryos.

${ }^{\ddagger}$ Resorbed (genotyped). 
A
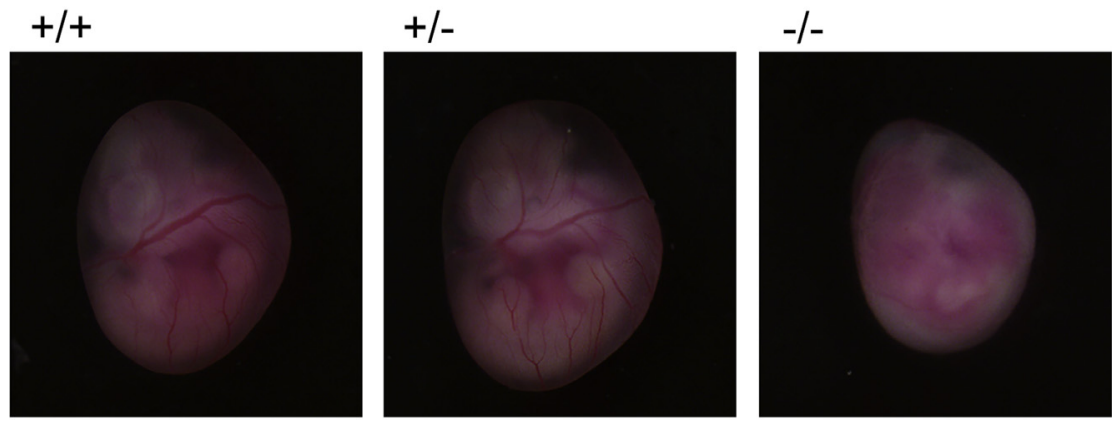

B
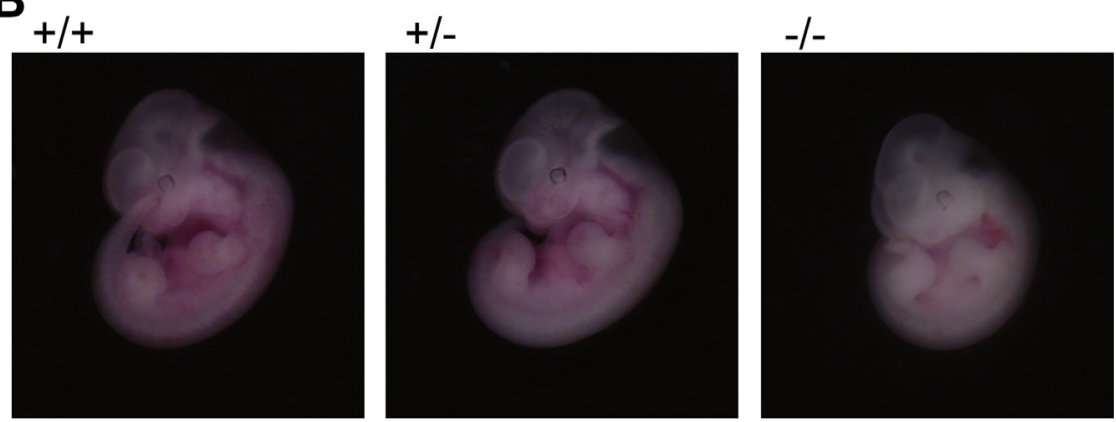

C
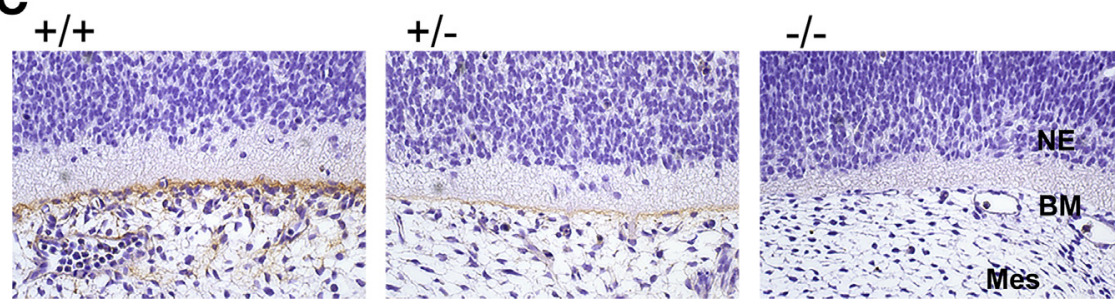

Figure $3 \mathrm{Col}_{5 \mathrm{a} 2^{-/-}}$embryonic lethality at approximately 12 days post conception (dpc). Col5a2 ${ }^{-/-}$embryos (11.5 dpc), shown inside (A) or removed from (B) their yolk sacs, are pale compared with $\mathrm{Col}_{5} \mathrm{a} 2^{+/+}$and $\mathrm{Col} 5 \mathrm{a} 2^{+/-}$littermates, with an absence of clearly visible vasculature caused by a paucity of blood in the cardiovascular system, and with some pooling of blood in the embryo and yolk sac. C: Parasagittal sections of $\mathrm{Col} 5 a 2^{+/+}, \mathrm{Col}_{5} \mathrm{a}^{+/-}$, and $\mathrm{Col} 5 \mathrm{a}^{-/-}$ embryos $11.5 \mathrm{dpc}$, immunostained with $\alpha 2(\mathrm{~V})$ specific antibody and counterstained with DAPI, have diminished or absent staining for $\alpha 2(V)$ in Col5a2 $2^{+/-}$and Col5a2 $2^{-/-}$embryos, respectively. BM, basement membrane; Mes, mesenchymal layer; $\mathrm{NE}$, neuroepithelium.

(reverse). Amplicons were resolved on $2.5 \%$ agarose gels, with approximately 350-bp and 510-bp bands corresponding to the wild-type and null alleles, respectively.

All mice were housed and treated in accordance with NIH guidelines, using protocols approved by the Research Animal Resources Center of the University of Wisconsin-Madison.

\section{Mouse Embryonic Fibroblast and Dermal Fibroblast Culturing and Immunoblotting}

Mouse embryonic fibroblasts (MEFs) were isolated from embryos 10.5 days post conception (dpc) as described ${ }^{23}$ and maintained in growth medium (Dulbecco's modified Eagle's medium, $10 \mathrm{IU} / \mathrm{mL}$ of penicillin-streptomycin) supplemented with $10 \%$ fetal bovine serum. For primary fibroblast isolation, fur was removed from the axillary regions of 15-week-old mice, and approximately $5 \times 5$-mm fullthickness skin excisions were collected and mechanically minced. Samples were then digested at $37^{\circ} \mathrm{C}$ for 24 hours in $0.5 \mathrm{mg} / \mathrm{mL}$ of type II collagenase (Worthington Biochemical Corp, Lakewood, NJ) in growth medium, supplemented with $20 \%$ fetal bovine serum. Samples were then centrifuged for 10 minutes at $1500 \times g$, and the pellet was resuspended in growth medium $/ 20 \%$ fetal bovine serum and plated for culturing.

For immunoblotting, cells were serum starved in growth medium supplemented with $75 \mu \mathrm{g} / \mathrm{mL}$ of ascorbate. Conditioned media were collected and concentrated on Amicon Centrifugal Filters (Millipore Corp, Billerica, MA). Samples were resolved on $6 \%$ acrylamide gels, and immunoblots were probed with antibody LF-67 directed against the human $\alpha 1(\mathrm{I})$ collagen C-telopeptide, ${ }^{24}$ with antibodies specific to either the $\alpha 1(\mathrm{~V})$ and $\alpha 2(\mathrm{~V})$ chain (see below), and with antiPCOLCE antibody (Sigma-Aldrich, St Louis, MO). All primary antibodies were diluted 1:1000 and detected with goat anti-rabbit secondary antibody (1:5000; Bio-Rad Laboratories, Hercules, CA).

\section{Quantitative Real-Time PCR}

RNA was isolated using Trizol, and isolated RNA was treated with DNase and further purified by phenol-chloroform extraction. RNA $(1 \mu \mathrm{g})$ was reverse transcribed using oligo(dT) nucleotides and SuperScript (Invitrogen Corp, Carlsbad, CA) to produce cDNA. Real-time PCR was performed using iQ SYBR Green Supermix (Bio-Rad) on a CFX96 real-time quantitative 

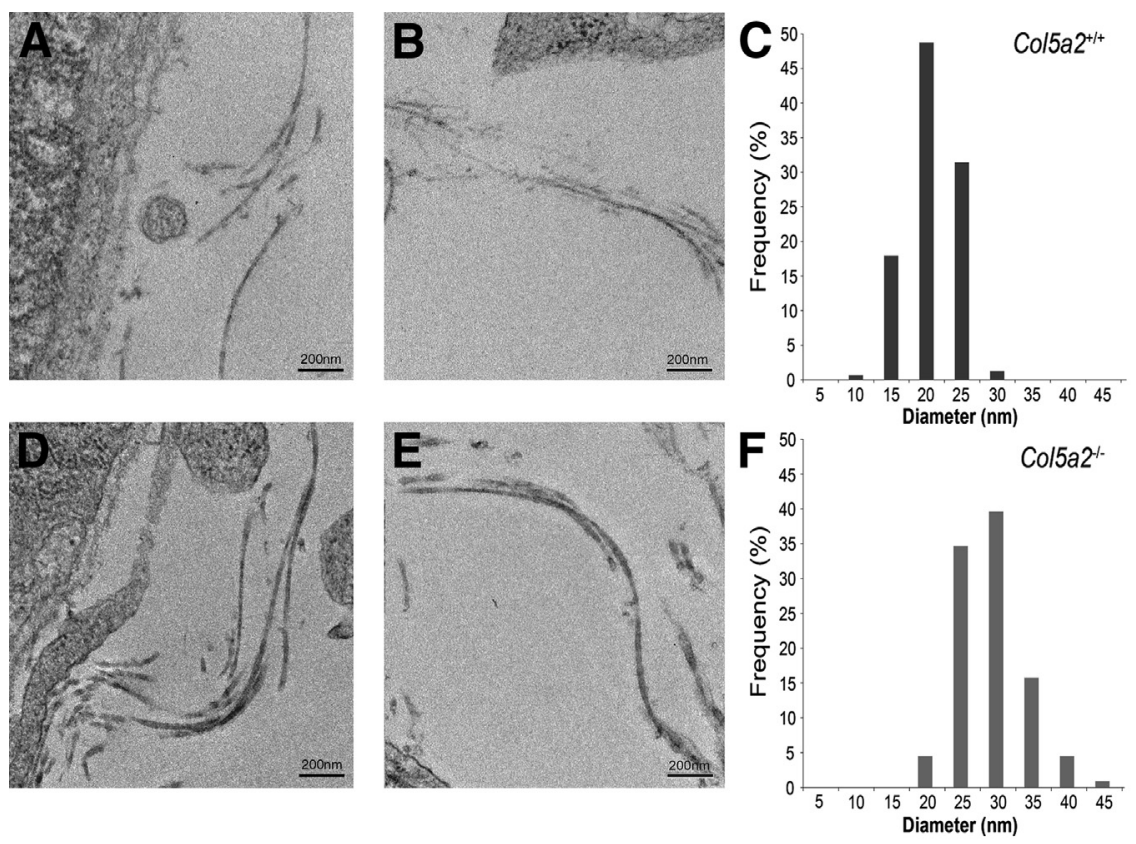

Figure 4 Transmission electron micrographs of collagen fibril architecture in $\mathrm{Col}_{5 \mathrm{a}}{ }^{+/-}$and Col5a2 ${ }^{-/-}$embryos. Col5a2 ${ }^{+/-}$(A and B) and Col5a2 ${ }^{-1-}$ ( $\mathbf{D}$ and $\left.\mathbf{E}\right)$ embryos have similar numbers of collagen fibrils, both juxtaposed to the basement membrane of the ectodermal layer (A and $\mathbf{D})$ and deeper in the mesenchyme ( $\mathbf{B}$ and $\mathbf{E})$. However, Col5a2 ${ }^{-/-}$embryo fibrils have diameters that are approximately $50 \%$ larger $(\mathbf{F})$ than $\mathrm{Col}_{5 a 2^{+/+}}$ diameters (C).
PCR (qPCR) system (Bio-Rad). Oligonucleotide primers used were as follows: Gapdh, 5'-AGCAATGCCTCCTGCACCACCAAC- $3^{\prime}$ (forward) and 5'-CCGGAGGGGCCATCCACAGTCT-3' (reverse); and Col5a2, 5'-GGAGAAGGAAACATCAGATTCA- $3^{\prime}$ (forward) and 5'-CCAAATTCCTGGTCTGCATT-3' (reverse).

\section{Antibodies and Histologic Analyses}

Antibodies specific to the cysteine-rich (CR) N-terminal globular domain of mouse $\alpha 2(\mathrm{~V})$ or to the poly (ADPribose) polymerase and variable domains of mouse $\alpha 1(\mathrm{~V})$ were raised against recombinant $\alpha 2(\mathrm{~V})$ and $\alpha 1(\mathrm{~V})$ fragments made in Escherichia coli. The oligonucleotide primer sets 5'-CATGCCATGGCCTGTACTCAACATGGACAGA- $3^{\prime}$ (forward) and 5'-CGCGGATCCATCTCCACCTCCAGTTTGTGG-3' (reverse) and 5'-CATGCCATGGGCTCAGGGGTAACGAAAACCA-3' (forward) and 5'-CGCGGATCCCCCTGGCCCTATCTCTGATGGA-3' (reverse) were used to amplify CR domain sequences from a full-length mouse pro- $\alpha 2(\mathrm{~V})$ clone, and poly (ADP-ribose) polymerase/ variable domains sequences from a full-length mouse pro$\alpha 1(\mathrm{~V})$ clone, respectively, in each case adding $\mathrm{NcoI}$ and BamHI restriction sites to the $5^{\prime}$ and $3^{\prime}$ ends, respectively, of the PCR products. The PCR products were then ligated between the NcoI and BamHI sites of vector pQE-60 (Qiagen, Valencia, CA) and transformed into JM109 cells. Cells were induced to express recombinant protein with addition of 0.5 $\mathrm{mmol} / \mathrm{L}$ isopropyl $\beta$-D-1-thiogalactopyranoside (SigmaAldrich). The recombinant His-tagged protein was subsequently extracted with BugBuster reagent (Millipore) and 6 $\mathrm{mol} / \mathrm{L}$ urea and purified on a $\mathrm{Co}^{++}$column, under denaturing conditions $(6 \mathrm{~mol} / \mathrm{L}$ urea) following the manufacturer's protocol (ThermoScientific, Rockford, IL). For the $\alpha 2(\mathrm{~V})$ CR fragment, 3-[(3-cholamidopropyl) dimethylammonio)]-1propanesulfonate was added to $1 \%$, and the sample was put on an Amicon Ultra-4 Centrifugal Filter with a 30-kDA molecular-weight cutoff to remove higher-molecularweight contaminants. Flowthroughs containing the highly purified recombinant proteins were collected, and 3-[(3cholamidopropyl) dimethylammonio)]-1-propanesulfonate and urea were dialyzed out before injection into rabbits. For the $\alpha 1(\mathrm{~V}) \mathrm{PARP} /$ variable domain fragment, sample eluted from the $\mathrm{Co}^{++}$column was run on a $10 \%$ acrylamide gel and stained with Coomassie Brilliant Blue. The corresponding band was excised from the gel and injected into rabbits. Both types of antibodies were affinity purified on columns of the recombinant immunogen.

For anti- $\alpha 2(\mathrm{~V})$ immunohistochemistry (IHC) and antiCD31 immunofluorescence, embryos were fixed in $10 \%$ formalin overnight, paraffin embedded, and processed into 5 $\mu \mathrm{mol} / \mathrm{L}$ parasagittal sections. Sections were incubated 1 hour with anti- $\alpha 2(\mathrm{~V})$ antibody, diluted 1:400, and incubated for 30 minutes with secondary ImmPRESS horseradish peroxidase anti-rabbit immunoglobulin (Vector Laboratories, Burlingame, CA). For CD31 staining, sections were incubated overnight with primary antibody (Dianova Laboratories, Hamburg, Germany) diluted 1:100, after heat-induced epitope retrieval in citrate buffer, followed by 30 minutes of incubation with ImmPRESS horseradish peroxidase anti-rat immunoglobulin. For confocal microscopy, embryos were fixed for 2 hours in $2 \%$ paraformaldehyde and then equilibrated overnight in $30 \%$ sucrose/PBS, followed by embedding in optimum cutting temperature compound. Frozen coronal sections $(5 \mu \mathrm{mol} / \mathrm{L})$ were incubated 1 hour with rabbit antibody LF-67, directed against the human $\alpha 1$ (I) collagen C-telopeptide, ${ }^{24}$ diluted 1:500, or guinea pig anti- $\alpha 1(\mathrm{~V}),{ }^{9}$ diluted 1:200. Sections were then incubated 30 minutes with Alexa Fluor 594 anti-guinea 
Table 2 Fibril Diameters in Ectoderm

\begin{tabular}{|c|c|c|c|c|c|c|}
\hline \multirow[b]{2}{*}{ Diameter } & \multicolumn{2}{|l|}{ Ectoderm* } & \multicolumn{2}{|c|}{ Deep ectoderm } & \multicolumn{2}{|l|}{ Combined } \\
\hline & $\begin{array}{l}\text { Col5a2 } \\
(n=15)\end{array}$ & $\begin{array}{l}\text { Col5a2 } \\
(n=15)\end{array}$ & $\begin{array}{l}\text { Col5a2 } \\
(n=13)\end{array}$ & $\begin{array}{l}\text { Col5a2 } \\
(n=4)\end{array}$ & $\begin{array}{l}\text { Col5a2 } \\
(n=28)\end{array}$ & $\begin{array}{l}\text { Col5a2 } \\
(n=29)\end{array}$ \\
\hline $\mathrm{SD}(\mathrm{nm})$ & 3.6 & 3.9 & 2.3 & 3.1 & 3 & 3.5 \\
\hline Median (nm) & 18.4 & 26.0 & 18.1 & 26.9 & 18.4 & 26.3 \\
\hline
\end{tabular}

*Ectoderm adjacent to the basement membrane.

pig IgG or Alexa Fluor 488 anti-rabbit IgG secondary antibodies, both diluted 1:1000. Confocal immunofluorescent images were captured at $2000 \times$ on a Leica DMI8000 (Leica Microsystems Inc, Buffalo Grove, IL) with a Yokogawa CSUX1 confocal scan head (Musashino, Tokyo, Japan).

For quantification of relative immunofluorescence intensity, images were captured using a Zeiss Axiophot 2 microscope with attached CCD camera (Carl Zeiss AG, Jena, Germany). A total of 3 embryos were analyzed per genotype with 3 to 5 highpower magnification $(400 \times)$ fields examined per embryo. Mean fluorescent intensities were determined using the histogram function of Photoshop (Adobe Systems Inc, San Jose, CA). Statistical analysis was performed using a Student's $t$-test.

\section{Biomechanical Analyses}

Thoracic aortas were cut into ascending and descending segments, and each segment was threaded with stainless steel hooks and separately analyzed ex vivo for breaking/tensile strength $\left(F_{\max }\right)$ and stiffness/compliance (incremental elastic modulus) using a TA-XT2 texture analyzer (Stable Micro Systems, Surrey, United Kingdom), as previously described. ${ }^{25}$ Tensile strength and elastic (automatic Young's) modulus of skin samples that had been stored frozen between strips of saline-soaked gauze were determined using a tensiometer (Instron Corp, Canton, MA) and were calculated as force per volume of tissue. Two skin samples were taken from the shaved back of each of $10 \mathrm{Col5a2^{+/- }}$ and $10 \mathrm{WT}$ mice.

\section{Transmission Electron Microscopy}

Mouse embryos (10.5 and $11.5 \mathrm{dpc}$ ) and subscapular dermis from postnatal day 50 (P50) and 15-week-old male mice were examined. For embryos, ectoderm and subjacent mesenchyme lateral to the neural tube were analyzed. Tissues were prepared for transmission electron microscopy essentially as described. ${ }^{26,27}$ Briefly, tissues were fixed in $4 \%$ paraformaldehyde, $2.5 \%$ glutaraldehyde, $0.1 \mathrm{~mol} / \mathrm{L}$ sodium cacodylate, $\mathrm{pH} 7.4$, with $8.0 \mathrm{mmol} / \mathrm{L} \mathrm{CaCl}_{2}$, postfixed with $1 \%$ osmium tetroxide. After dehydration in an ethanol series, followed by propylene oxide, the tissue samples were infiltrated and embedded in a mixture of Embed 812, nadic methyl anhydride, dodecenyl succinic anhydride, and DMP-30 (Electron Microscopy Sciences, Hatfield, PA). Thin (90-nm) sections were cut using a Leica UCT ultramicrotome and poststained with $2 \%$ aqueous uranyl acetate and $1 \%$ phosphotungstic acid, $\mathrm{pH}$ 3.2. Sections were examined and photographed at $80 \mathrm{kV}$ using a JEOL 1400 transmission electron microscope (JEOL, Peabody, MA) and Gatan Orius widefield side mount digital camera (Gatan, Pleasanton, CA).

\section{Statistical Analysis}

Analyses were performed with a 2-tailed Student's $t$-test, with differences considered significant at $P<0.05$.

\section{Results}

Generation of Mice with Floxed and Constitutively Null Col5a2 Alleles

Toward conditional knockdown of the Col5a2 gene, a targeting vector was designed that, on homologous recombination with the endogenous Col5a2 locus of embryonic stem cells, inserted loxP sites that flanked a 1544-bp region that contains the Col5a 2 first exon, and all sequence homology blocks conserved between $C o l 5 a 2$ and $C O L 5 A 2$ in the upstream promoter region and first intron enhancer sequences (Figure 1, A and B) (see Materials and Methods). Also flanked by the loxP sites was an frt-flanked neo ${ }^{r}$ cassette, subsequently excised from correctly targeted alleles by crosses of chimeric progeny with the ACTB:FLPe transgenic line of Flp deleter mice ${ }^{21}$ (Figure 1, A and C). To obtain mice with constitutively null Col5a 2 alleles, heterozygous Col5a $2^{\text {flox/+ }}$ mice were crossed with transgenic mice in which a cre-EGFP transgene is expressed in germ cells (see Materials and Methods), resulting in progeny in which floxed Col5a2 sequences were universally deleted in all tissues. qPCR of RNA isolated from mouse embryo fibroblasts (MEFs) derived from Col5 $\mathrm{a} 2^{+/+}$and Col5 $\mathrm{a} 2^{-/-}$embryos $10.5 \mathrm{dpc}$ had a total absence of $\alpha 2(\mathrm{~V})$ RNA in the latter, and immunoblotting of conditioned media from the same MEFs similarly found a total absence of detectable $\alpha 2(\mathrm{~V})$ collagen chains in Col5a $2^{-1-}$ medium (Figure 2, A and B), results consistent with the conclusion that the mutant Col5a2 allele used in these studies is truly null.

\section{Col5a2 ${ }^{-/-}$Progeny Are Embryonic Lethal at Approximately $12 \mathrm{dpc}$}

Col5a $2^{-1-}$ embryos, homozygous for Col5a2 null alleles, were embryonic lethal (Table 1), with Col5a $2^{-1-}$ embryos alive and phenotypically normal on gross inspection at 10.5 

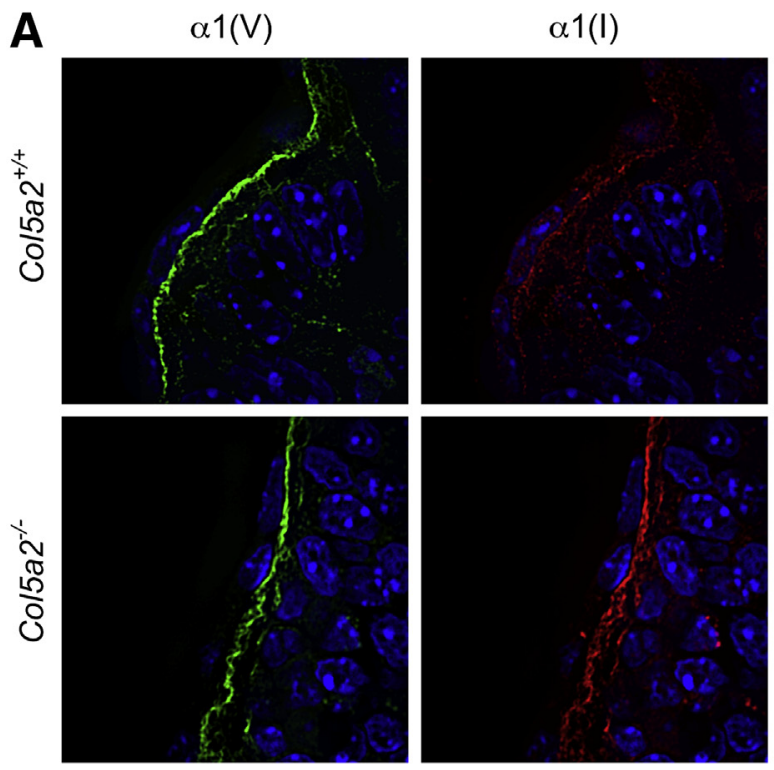

B

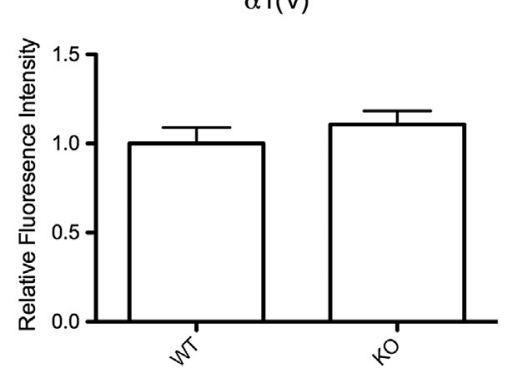

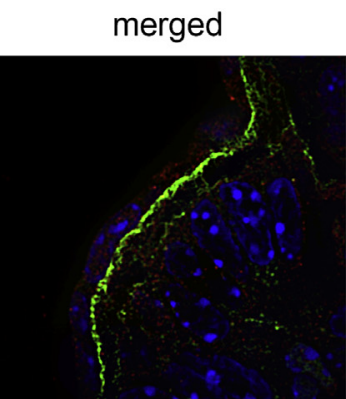

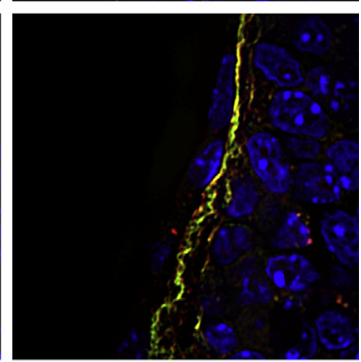

$\alpha 1(I)$

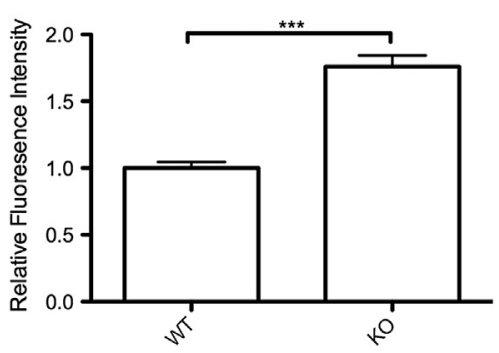

Figure 5 Collagen I fibrils co-localize with $\alpha 1(\mathrm{~V})$ chains in Col5a2 ${ }^{-/-}$embryos. A: Sections from $\mathrm{Col}_{5} \mathrm{a}^{+/+}$and $\mathrm{Col} 5 \mathrm{a} 2^{-/-}$embryos were subjected to immunofluorescent staining with antibodies specific for the $\alpha 1(\mathrm{~V})$ chain (green) and for the $\alpha 1$ (I) chain of collagen I (red) and were also stained with DAPI (blue). The yellow signal indicates areas in which green and red signals overlap and thus areas of co-localization between $\alpha 1(\mathrm{~V})$ chains and collagen I. B: Signal for $\alpha 1$ (I) chain was consistently brighter in Col5a2 ${ }^{-/-}$sections. Quantification used three microscopic fields from each of the three embryos of every genotype. Error bars indicate SEM. ${ }^{* * * P}<0.001$. KO, knockout; WT, wild type. dpc (not shown) but developing pallor, congestion of blood, and an absence of clearly visible vasculature, due to a paucity of blood in the cardiovascular system, at $11.5 \mathrm{dpc}$ (Figure 3, A and B), with a lack of heart beat noted in some embryos at $11.5 \mathrm{dpc}$ and death at 12 to $12.5 \mathrm{dpc}$ (Table 1). The finding that the decrease in observable blood-filled vessels is not due to a decrease or change in the distribution of blood vessels was confirmed by immunofluorescent staining with antibody to the endothelial cell marker CD31 (platelet endothelial cell adhesion molecule), which had a similar pattern and density for CD31 signal in both Col5a2 $2^{+/+}$and Col5a2 ${ }^{-/-}$embryos $12.5 \mathrm{dpc}$ (Supplemental Figure S1). IHC staining of embryos $11.5 \mathrm{dpc}$ with anti$\alpha 2(\mathrm{~V})$ chain antibody revealed the absence of detectable $\alpha 2(\mathrm{~V})$ chains in Colsa2 ${ }^{-1-}$ embryos and the diminution of $\alpha 2(\mathrm{~V})$ chain deposition in $\mathrm{Col}_{5} 2^{+/-}$embryos compared with $\mathrm{Col} 5 \mathrm{a2}^{+/+}$embryos (Figure 3C), thus supporting the conclusion that the mutant Col5a2 allele used in these studies is truly null.

Col5 $\mathrm{a}^{-1-}$ embryos $10.5 \mathrm{dpc}$ had collagen fibrils, similar in numbers to those in WT littermates, both in deeper mesenchymal regions and juxtaposed to the ectodermal basement membrane (Figure 4), although $\mathrm{ColSa}^{-1-}$ fibrils in both regions had means \pm SD diameters $(26.7 \pm 3.5 \mathrm{~nm})$ approximately $50 \%$ larger than WT counterparts (18.2 \pm 3.0 $\mathrm{nm}$ ) (Table 2). In contrast, it has been reported that
Col5a1 ${ }^{-1-}$ embryos 10.5 dpc lack collagen fibrils in the mesenchyme and have only a small number of very large diameter fibrils, with misshapen profiles, that are limited to the ectodermal basement membrane zone at the stromal interface. $^{9}$

\section{$\alpha 1(V)$ Collagen Chains Associate with Collagen I Fibrils in the Absence of $\alpha 2(V)$ Collagen Chains}

Because $\alpha 2(\mathrm{~V})$ chains do not appear to be capable of forming stable $\alpha 2(\mathrm{~V})$ homotrimers in the absence of $\alpha 1(\mathrm{~V})$ chains with which to combine, ${ }^{8,28}$ the phenotype of $\mathrm{Col}_{\mathrm{a}} \mathrm{I}^{-1-}$ embryos is thought to be associated with total absence of both $\alpha 1(\mathrm{~V})$ and $\alpha 2(\mathrm{~V})$ chains because unstable, nontrimeric $\alpha 2(\mathrm{~V})$ chains would be degraded rather than incorporated into the ECM in Col5 $\mathrm{al}^{-1-}$ tissues. In contrast, the phenotype of Col5a2 $2^{-1-}$ embryos should be associated not only with the absence of normal $\alpha 1(\mathrm{~V})_{2} \alpha 2(\mathrm{~V})$ heterotrimers but also with the presence of aberrant $\alpha 1(\mathrm{~V})_{3}$ homotrimers because $\alpha 1(\mathrm{~V})$ chains in the absence of $\alpha 2(\mathrm{~V})$ chains form stable $\alpha 1(\mathrm{~V})_{3}$ homotrimers. ${ }^{28-30}$

The absence of type I collagen fibrils in $\mathrm{Col}^{2} \mathrm{al}^{-1-}$ embryos has led to the suggestion that normal collagen $\mathrm{V}$, consisting of $\alpha 1(\mathrm{~V})_{2} \alpha 2(\mathrm{~V})$ heterotrimers, plays an important role in initiating collagen I fibril assembly in early embryogenesis. ${ }^{9}$ Thus, the appearance of collagen fibrils in $\mathrm{Col}_{5} \mathrm{a}^{-1-}$ embryos, 

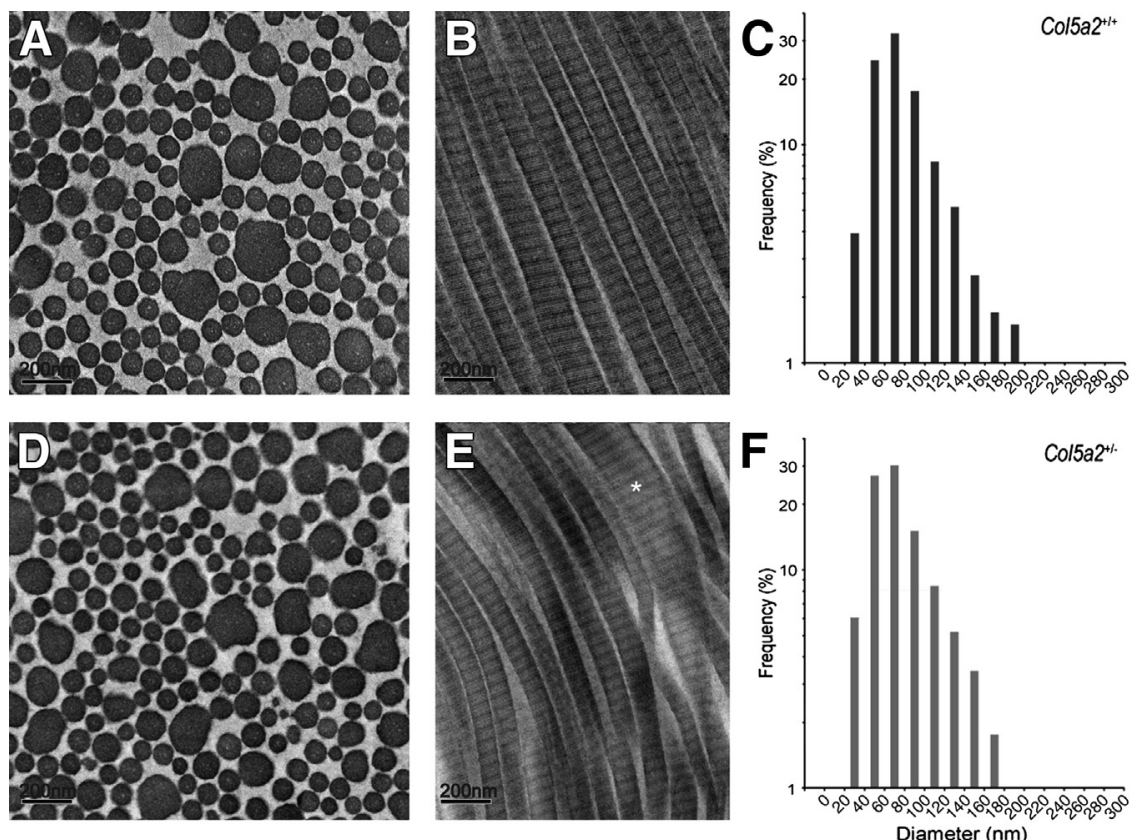

Figure 6 Postnatal Col5a2 $2^{+/-}$heterozygotes have abnormalities in collagen fibril morphology. Transmission electron micrographs of collagen fibrils in cross section (A and $\mathbf{D}$ ) and longitudinal section ( $\mathbf{B}$ and $\mathbf{E})$ in the skin of P5O Col5a2 $2^{+/+}(\mathbf{A}$ and $\mathbf{B})$ and $\mathrm{Col}_{5 a 2^{+/-}}(\mathbf{D}$ and $\mathbf{E})$ mice. A thicker fibril with irregular contours is marked by an asterisk. Fibril diameter distributions were a mean of $105.2 \mathrm{~nm}, \mathrm{a}$ median of $91.6 \mathrm{~nm}$, and an SD of $15.72 \mathrm{~nm}$ for postnasal day $50 \mathrm{Col}^{\mathrm{a} 2^{+/+}}$mice (C) and a mean of $101.8 \mathrm{~nm}$, a median of $89.7 \mathrm{~nm}$, and an SD of 13.3 $\mathrm{nm}$ for $\mathrm{Col}_{5 a 2^{+/-}}$mice (F). $n=38(\mathbf{C}) ; n=38(\mathbf{F})$. similar in number to those in WT embryos, suggests that $\alpha 1(\mathrm{~V})_{3}$ homotrimers can, at least to some extent, compensate for loss of $\alpha 1(\mathrm{~V})_{2} \alpha 2(\mathrm{~V})$ heterotrimers and play a role in initiating collagen I fibril assembly. Because this implies interaction between $\alpha 1(\mathrm{~V})_{3}$ homotrimers and collagen I fibrils, confocal immunofluorescent microscopy was used to determine whether $\alpha 1(\mathrm{~V})$ chains co-localize with collagen I fibrils. $\alpha 1(\mathrm{~V})$ chains indeed co-localized with collagen I fibrils in Colsa2 $2^{-/-}$embryos (Figure 5). Interestingly, a consistent difference between $\mathrm{Col}_{\mathrm{a} 2} 2^{-/-}$and $\mathrm{Col} 5 \mathrm{a2}^{+/+}$embryos was a stronger immunofluorescent signal for collagen $\mathrm{I}$ in the former. Because the MEFs from Col5a2 $2^{+/+}$and Col5a2 ${ }^{-1-}$ embryos $11.5 \mathrm{dpc}$ had similar levels of procollagen I expression and similar levels of the biosynthetic processing of procollagen into mature collagen I monomers necessary for deposition into ECM (Supplemental Figure S2), differences in the strength of immunofluorescent staining for collagen I may involve differences in fibril configuration, with a more open configuration to Col5a2 $2^{-1-}$ fibrils that is more conducive to IHC staining of collagen I.

\section{Postnatal Col5a2 ${ }^{+/-}$Heterozygotes Have Abnormalities in Collagen Fibril Morphology}

Because null alleles for COL5A2 have yet to be detected in cEDS patients ${ }^{7}$ or associated with any other human conditions, possible effects of haploinsufficiency for the $\alpha 2(\mathrm{~V})$ chain remain unknown. Thus, it was of great interest to ascertain whether postnatal Col5a $2^{+/-}$mice had abnormalities of their dermal collagen fibrils and, if so, whether such fibrils had the marked variability in diameters and subpopulations of large-diameter collagen fibril aggregates with abnormal cauliflower-like contours seen in cEDS skin. ${ }^{6}$
qPCR of RNA isolated from dermal fibroblasts derived from the skin of $\mathrm{Col}_{5} a 2^{+/+}$and $\mathrm{Col}_{5} a 2^{+/-}$mice and immunoblotting of conditioned media from the same cells confirmed that Col5 $\mathrm{a}^{+/-}$heterozygous dermal fibroblasts contain half the amount of $\alpha 2(\mathrm{~V})$ RNA (Figure 2C) and produce half the amount of $\alpha 2(\mathrm{~V})$ chains (Figure 2D) as Col5a $2^{+/+}$dermal fibroblasts, consistent with the expected $\alpha 2(\mathrm{~V})$ haploinsufficiency in $\mathrm{Col} 5 \mathrm{a2}^{+/-}$mouse skin. On inspection of the skin of P50 mice by transmission electron microscopy, although there were no obvious differences in $\mathrm{Col}_{5 \mathrm{a}} \mathrm{C}^{+/+}$and $\mathrm{Col} 5 \mathrm{a} 2^{+/-}$collagen fibril morphology in cross section (Figure 6, A and D), irregularities in fibril contours of a portion of Col5a2 $2^{+/-}$fibrils in longitudinal views were a consistent feature, with some fibrils thicker than seen in $\mathrm{Colsa2}^{+/+}$skin (Figure 6, B and E). Quantitation of diameters of the cross sectioned fibrils revealed that in addition to irregular contours, there was a slight increase in the range of fibril diameters in P50 Col5a2 ${ }^{+/-}$skin, compared with P50 Col5a2 ${ }^{+/+}$skin, with some skewing of the range toward a small subpopulation of large (eg, 180 $\mathrm{nm}$ ) fibrils (Figure 6, C and F). Fibrils with irregular contours persisted in the skin of 15 -week-old $\mathrm{ColS}^{2} 2^{+/-}$mice, although there was no longer an increased range in fibril diameters compared with the skin of 15 -week-old Colsa2 $2^{+/+}$ mice (Supplemental Figure S3).

\section{Skin of Adult Col5a2 $2^{+/-}$Heterozygotes Has Increased Extensibility and Decreased Tensile Strength Compared with WT Mice Skin}

cEDS skin is characterized by hyperextensibility and decreased tensile strength. ${ }^{6}$ To determine whether haploinsufficiency for the $\alpha 2(\mathrm{~V})$ chain can lead to such features, 

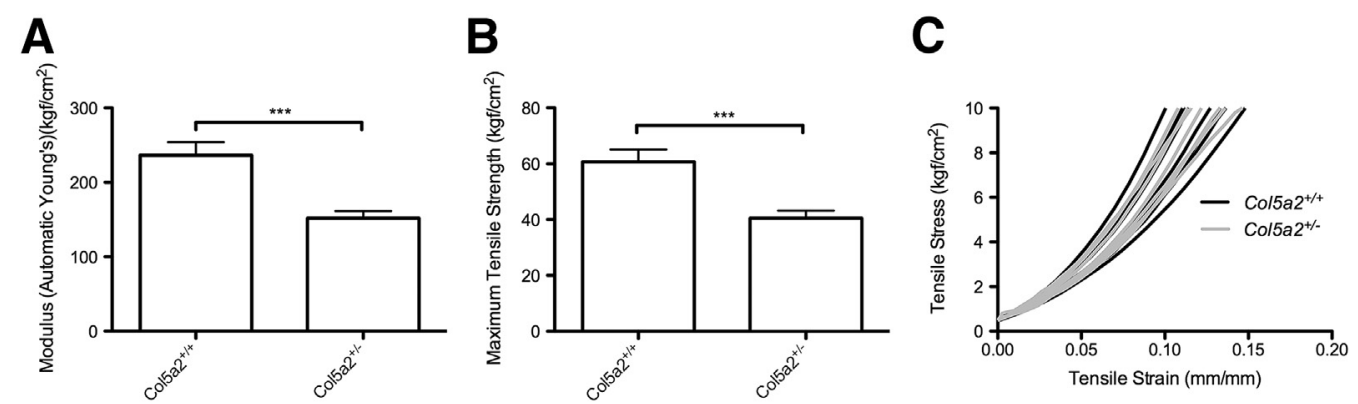

Figure 7 Col5a2 $2^{+/-}$heterozygous adult skin has increased extensibility and decreased tensile strength. Young's modulus (stiffness) (A) and tensile strength measurements (B) are shown for the skin of 15-week-old Col5a2 ${ }^{+/+}$and Col5a2 ${ }^{+/-}$mice. Error bars indicates SEM. C: Low-force areas of the stress-strain curves from the tensiometer data for Col5a2 ${ }^{+/+}$(black) and Col5a2 ${ }^{+/-}$(gray) samples. ${ }^{* * *} P<0.001$.

skin samples from 15-week-old Col5a2 ${ }^{+/-}$and WT skin mice were quantitatively compared for extensibility and fragility via tensiometer. The skin of Colsa2 $2^{+/-}$heterozygotes was hyperextensible (Figure 7A), with $\mathrm{Col} 5 \mathrm{ar}^{+/-}$skin displaying a means \pm SD modulus of $151.8 \pm 9.84 \mathrm{kgf}$ (kilogram-feet tensile stress) $/ \mathrm{cm}^{2}$ compared with a modulus of $219.8 \pm 13.83 \mathrm{kgf} / \mathrm{cm}^{2}$ for WT skin. Col5 $\mathrm{a}^{+/-}$skin also had less tensile (breaking) strength (Figure 7B) than the skin of WT controls, with $\mathrm{Col} 5 \mathrm{a} 2^{+/-}$skin failing at $40.50 \pm 2.76$ $\mathrm{kgf} / \mathrm{cm}^{2}$, compared with failure at $62.25 \pm 4.36 \mathrm{kgf} / \mathrm{cm}^{2}$ for WT skin. Thus, the tensile strength of $\mathrm{Col} 5 \mathrm{a} 2^{+/-}$skin was reduced approximately $35 \%$ compared with WT. In a similar comparison, via tensiometer, a previous study found the tensile strength of skin from Colsal ${ }^{+/-}$heterozygotes to be approximately $48 \%$ reduced compared with that of WT littermate controls. ${ }^{10}$ Thus, the stiffness and tensile strength of Col5 $\mathrm{a}^{+/-}$skin are reduced compared with WT skin, but the tensile strength of $\mathrm{Col} 5 \mathrm{a} 2^{+/-}$skin is apparently not reduced to the same extent as is the skin of $\mathrm{ColFal}^{+/-}$heterozygotes, a mouse model for cEDS. Interestingly, although the dermal hyperextensibility of $\mathrm{Cols} \mathrm{al}^{+/-}$mice is visually apparent when they and WT controls are lifted by their dorsal skin, ${ }^{10}$ such hyperextensibility is not clearly evident for the skin of Col5a2 $2^{+/-}$mice when they and WT controls are similarly manipulated (Supplemental Figure S4). In fact, although tensiometer data (Figure 7, A and B) are usually obtained at relatively high levels of applied force, analysis of the lowforce areas of the stress-strain curves from the tensiometer data revealed the stress-strain curves of several samples of $\mathrm{Col} \mathrm{a2}^{+/-}$and WT skin to overlap (Figure 7C), suggesting an absence of significant differences in elasticity at low force. Thus, although skin haploinsufficient for $\alpha 2(\mathrm{~V})$ chains is clearly more fragile and more elastic than WT, it is not clear whether such differences would be apparent under the lowforce methods used in tests for cEDS in a clinical setting.

\section{Col5a2 $2^{+/-}$Heterozygous Adults Have Aortas with Increased Compliance and Decreased Tensile Strength Compared with WT Mice}

cEDS patients have an increased incidence of aortic root dilation and pouching of aortic sinuses, both presumably reflecting increased aortic elasticity. ${ }^{11-13}$ In addition, easy bruising and bleeding are associated with cEDS, ${ }^{6}$ also indicative of deficits in physical properties of the vasculature. To determine the extent to which physical properties of aortas might be affected by haploinsufficiency for $\alpha 2(\mathrm{~V})$ chains, a biomechanical comparison was made of the ascending and descending aortas of $\mathrm{ColSa}^{+/-}$and WT mice. There was a $51 \%$ reduction of tensile strength (breaking strength) $(13.09 \pm 1.47$ versus $26.57 \pm 2.55 ; P=0.0006)$ and a $59 \%$ reduction of elastic modulus (stiffness) $(18.46 \pm 3.06$ versus $45.32 \pm 5.87 ; P=0.00516)$ of the $\mathrm{Col} \mathrm{a} \mathrm{2}^{+/-}$ascending aortas compared with WT mice (Figure 8, A and B), whereas there was a $33 \%$ reduction of tensile strength $(8.30 \pm 0.92$ versus $12.46 \pm 0.93 ; P=0.0078)$ and a $32 \%$ trend of reduced elastic modulus $(13.09 \pm 2.28$ versus $19.33 \pm 1.88$; $P=0.0562)$ in $\mathrm{Col}_{\mathrm{a}} \mathrm{2}^{+/-}$descending aortas compared with WT aortas (Figure 8). Interestingly, although the Col5a2 $2^{+/-}$ genotype had greater effects on the tensile strength and elasticity of the ascending aorta (51\% reduction and 59\% reduction, respectively) than on the tensile strength and elasticity of the descending aorta (33\% and 32\%, respectively), it has previously been reported that the Colsal ${ }^{+/-}$genotype has greater effects on the tensile strength and elasticity of the descending aorta (60\% and 68\%, respectively) than on the tensile strength and elasticity of the ascending aorta (36\% and $37 \%$, respectively). ${ }^{10}$

\section{Discussion}

In the years since the initial demonstration that mutations in the genes for the $\alpha 1(\mathrm{~V})^{4}$ and $\alpha 2(\mathrm{~V})^{5}$ collagen chains can underlie cEDS, it has become apparent that mutations in these genes underlie the disease in most, if not all, patients with cEDS. ${ }^{7}$ Most cEDS patients are heterozygous for COL5A1 null alleles and thus are haploinsufficient for the $\alpha 1(\mathrm{~V})$ chain. A lesser number of cEDS patients are heterozygous for COL5A1 missense mutations, some of which affect secretion or stability, thus resulting in functional haploinsufficiency, but some of which probably represent true structural mutations that result in stable, but abnormal, $\alpha 1(\mathrm{~V})$ chains that combine with $\alpha 2(\mathrm{~V})$ chains and are incorporated into consequently abnormal collagen fibrils. ${ }^{7} \mathrm{~A}$ 

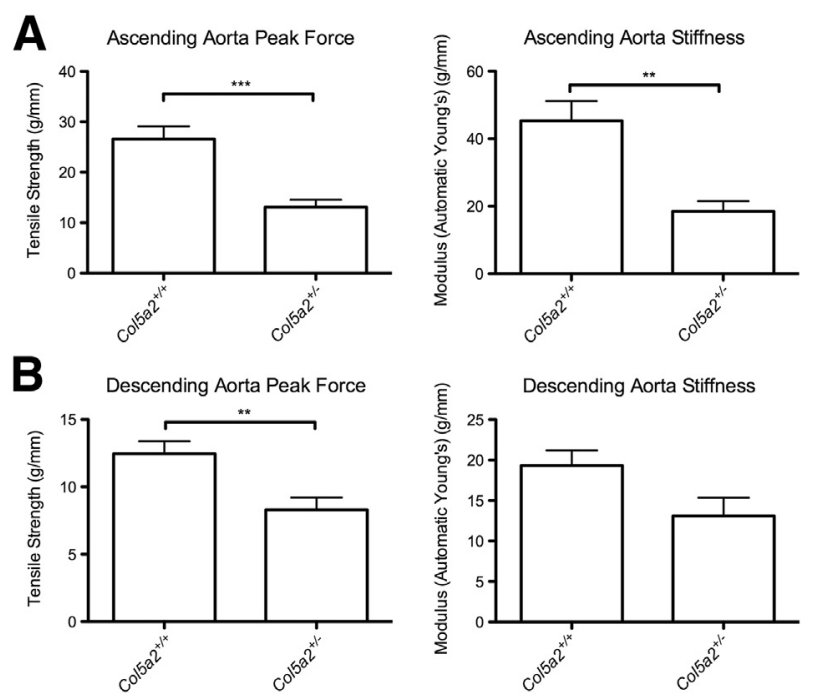

Figure $8 \mathrm{Col}_{5 \mathrm{a} 2^{+/-}}$heterozygous adults have aortas with increased compliance and decreased tensile strength. Biomechanical measurements of the tensile strength (peak force) and stiffness of ascending (A) and descending (B) aortas harvested from Col5a2 $2^{+/+}$and $\mathrm{Col}_{5 \mathrm{a} 2^{+/-}}$15-weekold mice. Error bars indicate SEM. ${ }^{* *} P<0.01,{ }^{* * *} P<0.001$.

third subset of cEDS patients are heterozygous for missense mutations of the $\alpha 2(\mathrm{~V})$ chain gene COL5A2. ${ }^{7}$ However, despite the relatively large number of cEDS patients analyzed to date, COL5A2 null alleles have yet to be detected. This has raised the issue of whether $\alpha 2(\mathrm{~V})$ chain haploinsufficiency leads to cEDS or, if not, what phenotype might result.

Previously, a mouse model was reported in which a small in-frame deletion of N-terminal noncollagenous $\alpha 2(\mathrm{~V})$ sequences was thought to result in functionally null Col5a2 alleles. ${ }^{15}$ However, the small in-frame deletion in this allele should not have interfered with either assembly or secretion of $\alpha 1(\mathrm{~V})_{2} \alpha 2(\mathrm{~V})$ heterotrimers, and appropriately sized $\alpha 2(\mathrm{~V})$ chains were observable on immunoblots of mutant skin. ${ }^{14}$ Heterozygotes for this allele were essentially phenotypically normal, but homozygotes died postnatally, with approximately 5\% surviving after weaning, living a normal life span, ${ }^{14,15}$ and having fragile, hyperextendible skin that contained unusually large-diameter collagen fibrils that included fibril aggregates, ${ }^{14}$ a skin phenotype thus reminiscent of cEDS. However, the recessive nature of the phenotype of these mice, along with spinal abnormalities (kypholordosis) not characteristic of cEDS, argues against the possibility that such mice represent a model for cEDS. Moreover, phenotypic differences between mice with the previously reported mutant Col5a 2 allele and the mice described here, with truly null Col5a2 alleles, indicate that the previously described allele was not functionally null. ${ }^{14,15}$ Instead, it seems probable that the non-cEDS phenotype of the previous mutant Col5a 2 model results from expression of a stable aberrant $\alpha 2(\mathrm{~V})$ chain that is incorporated into aberrant $\alpha 1(\mathrm{~V})_{2} \alpha 2(\mathrm{~V})$ heterotrimers and into a consequently aberrant ECM. ${ }^{14,15}$
We have described, for the first time to our knowledge, the phenotypic consequences of null Colsa2 alleles. Colsa $2^{-/-}$homozygotes die at approximately $12 \mathrm{dpc}$, with pallor, congestion of blood, and an absence of clearly visible vasculature because of a paucity of blood in the cardiovascular system. The cardiovascular signs in $\mathrm{Col}_{5} \mathrm{a}^{-1-}$ embryos are thus similar to those previously reported for $\mathrm{Colsal}^{-1-}$ embryos, ${ }^{9}$ and together these findings are indicative of an important role for collagen $\mathrm{V} \alpha 1(\mathrm{~V})_{2} \alpha 2(\mathrm{~V})$ heterotrimers in early cardiovascular integrity. However, $\mathrm{Col} \mathrm{al}^{-1-}$ embryos die at approximately $10.5 \mathrm{dpc},{ }^{9} 2$ days earlier in gestation than the Col5a2 $2^{-/-}$embryos described here. Because $\alpha 2(\mathrm{~V})$ chains are thought to be unstable in the absence of $\alpha 1(\mathrm{~V})$ chains with which to combine, ${ }^{8,28}$ the phenotype of $\mathrm{ColFal}^{-1-}$ embryos likely results from a complete absence of both $\alpha 1(\mathrm{~V})$ and $\alpha 2(\mathrm{~V})$ chains and thus a lack of collagen V. However, in the absence of $\alpha 2(\mathrm{~V})$ chains with which to combine, $\alpha 1(\mathrm{~V})$ chains form stable $\alpha 1(\mathrm{~V})_{3}$ homotrimers. ${ }^{28,29}$ Thus, the 2 additional days of embryonic survival of $\mathrm{Coll}_{\mathrm{a} 2^{-/-}}$, compared with $\mathrm{Col} 5 \mathrm{al}^{-1-}$ embryos, suggests that $\alpha 1(\mathrm{~V})_{3}$ homotrimers can functionally compensate, in part, for the loss of $\alpha 1(\mathrm{~V})_{2} \alpha 2(\mathrm{~V})$ heterotrimers.

The previously reported lack of identifiable mesenchymal collagen fibrils in $\mathrm{Col}_{5 \mathrm{al}}{ }^{-1-}$ embryos has led to the suggestion that collagen $\mathrm{V} \alpha 1(\mathrm{~V})_{2} \alpha 2(\mathrm{~V})$ heterotrimers are normally required for a nucleation event in the formation of collagen fibrils early in embryogenesis. ${ }^{9}$ In contrast, the presence of mesenchymal collagen fibrils similar in number and periodicity in Col5a $2^{-1-}$ and WT embryos reported here suggests that $\alpha 1(\mathrm{~V})_{3}$ homotrimers can also subserve this nucleating function, a role consistent with our finding of colocalization of $\alpha 1(\mathrm{~V})$ chains and collagen I fibrils in $\mathrm{Cols}^{-1-}$ embryos. However, Col5a2 $2^{-/-}$collagen fibrils were of abnormally large diameters and consistently had a stronger immunofluorescent signal than the WT fibrils, suggesting an abnormal configuration more open and accessible to antibodies than in WT fibrils. Thus, although $\alpha 1(\mathrm{~V})_{3}$ homotrimers appear to have the ability to compensate for the loss of $\alpha 1(\mathrm{~V})_{2} \alpha 2(\mathrm{~V})$ heterotrimers in the nucleation of early embryonic collagen fibril formation, this ability seems imperfect and results in malformed fibrils.

The triple helical domains of $\alpha 1(\mathrm{~V})_{2} \alpha 2(\mathrm{~V})$ heterotrimers are likely buried within collagen I fibrils into which they are incorporated, parallel to the long axis of the fibril, whereas the large $\mathrm{N}$-terminal globular sequences of the $\alpha 1(\mathrm{~V})$ chains of these heterotrimers protrude at an angle to the long axis of the fibril, projecting beyond the fibril surface, where they are thought to play roles in controlling fibril shape and diameter. ${ }^{1}$ We speculate that although $\alpha 1(\mathrm{~V})_{3}$ homotrimers may have the ability to nucleate fibril formation, fibrils that incorporate such homotrimers would need to accommodate $\mathrm{N}$-terminal globular domains of three, rather than the normal two, a1(V) N-terminal globular domains projecting through gaps in the fibril surface. They would also need to accommodate $\alpha 1(\mathrm{~V})_{3}$ triple helical domains with physical 
differences (eg, in charge and diameter) from the $\alpha 1(\mathrm{~V})_{2} \alpha 2(\mathrm{~V})$ triple helices normally accommodated within fibril interiors. Thus, the need to accommodate these differences may explain the abnormal configuration of Col5a $2^{-1-}$ collagen fibrils.

Postnatal Cols $\mathrm{a}^{+/-}$heterozygotes had relatively mild abnormalities in collagen fibril morphology. At P50 this included irregular contours and a slight increase in the range of fibril diameters in Col5a2 $2^{+-}$skin, compared with WT skin, with some skewing of the range toward a small subpopulation of large fibrils, suggestive of some disruption of lateral growth regulation. Although at 15 weeks of age there was no longer an increased range in fibril diameters compared with WT skin, dermal collagen fibrils with irregular contours remained evident. However, although $\mathrm{Col} 5 \mathrm{a} 2^{+/-}$mice have abnormally contoured dermal collagen fibrils, they lack the very large diameter cauliflower-shaped dermal collagen fibrils pathognomonic of cEDS and found in the Col5al ${ }^{+/-}$cEDS mouse model. Nevertheless, $\mathrm{Col}_{5} \mathrm{a}^{+/-}$skin has markedly increased elasticity and markedly decreased tensile strength, compared with WT skin, although the reduction in the tensile strength of $\mathrm{Col}_{5} \mathrm{2}^{+/-}$skin (35\% less than WT skin) was less than the reduction in tensile strength previously reported for $\mathrm{Col}_{5} \mathrm{al}^{+/-}$ skin $\left(48 \%\right.$ less than WT skin). ${ }^{10}$ However, these observations were made under conditions in which skin was placed under high strain.

Notably, in terms of how humans haploinsufficient for $\alpha 2(\mathrm{~V})$ chains might present clinically, differences in the extensibility of Col5a2 $2^{+-}$and WT skin were not evident on low strain manual manipulation or via tensiometer under conditions of low strain. Thus, although $\mathrm{Col} \mathrm{a} 2^{+/-}$skin is clearly more fragile and extensible than WT skin, the lack of apparent differences with WT skin under conditions of low strain may explain the lack of heterozygous $\mathrm{COL} 5 \mathrm{~A} 2^{+/-}$individuals thus far diagnosed as having $\operatorname{cEDS}^{7}$ because clinicians typically use low-force methods to ascertain whether a diagnosis of cEDS is warranted, essentially measuring elasticity at very low strain ( $2 \%$ to $5 \%) .{ }^{31}$ Nevertheless, the data presented here suggest that human individuals with a COL $5 \mathrm{~A}^{+/-}$genotype are likely to be more susceptible to skin tearing and wounding than normal, even though they might not be diagnosed as having frank cEDS.

In the context of clinical presentation, it is of interest that Colsa2 $2^{+/-}$aortas, like those of the Col5al ${ }^{+/}$cEDS mouse model,${ }^{10}$ have marked elasticity and fragility of the aorta. This and the cardiovascular deficits seen in $\mathrm{Col} \mathrm{a2}^{-/-}$embryos suggest that $\operatorname{COL} 5 A 2^{+/-}$humans might, like cEDS patients, ${ }^{6}$ have easy bruising and bleeding, indicative of deficits in the physical properties of their vasculature. Of great potential interest was the finding that the Cols $\mathrm{a}^{+/-}$genotype appears to have greater effects on reducing the tensile strength and increasing the elasticity of the ascending aorta than the previously described $\mathrm{Col} 5 \mathrm{al}^{+/-}$genotype. ${ }^{10}$ Thus, the studies presented here suggest the possibility that a $C O L 5 A 2^{+/-}$ genotype might predispose to thoracic aortic aneurysms and acute aortic dissections.

\section{Supplemental Data}

Supplemental material for this article can be found at http://dx.doi.org/10.1016/j.ajpath.2015.03.022.

\section{References}

1. Fichard A, Kleman JP, Ruggiero F: Another look at collagen V and XI molecules. Matrix Biol 1995, 14:515-531

2. Birk DE, Fitch JM, Babiarz JP, Linsenmayer TF: Collagen type I and type $\mathrm{V}$ are present in the same fibril in the avian corneal stroma. J Cell Biol 1988, 106:999-1008

3. Birk DE, Fitch JM, Babiarz JP, Doane KJ, Linsenmayer TF: Collagen fibrillogenesis in vitro: interaction of types I and $\mathrm{V}$ collagen regulates fibril diameter. J Cell Sci 1990, 95(pt 4):649-657

4. Toriello HV, Glover TW, Takahara K, Byers PH, Miller DE, Higgins JV, Greenspan DS: A translocation interrupts the COL5A1 gene in a patient with Ehlers-Danlos syndrome and hypomelanosis of Ito. Nat Genet 1996, 13:361-365

5. Richards AJ, Martin S, Nicholls AC, Harrison JB, Pope FM, Burrows NP: A single base mutation in COL5A2 causes Ehlers-Danlos syndrome type II. J Med Genet 1998, 35:846-848

6. De Paepe A, Malfait F: The Ehlers-Danlos syndrome, a disorder with many faces. Clin Genet 2012, 82:1-11

7. Symoens S, Syx D, Malfait F, Callewaert B, De Backer J, Vanakker O, Coucke P, De Paepe A: Comprehensive molecular analysis demonstrates type $\mathrm{V}$ collagen mutations in over $90 \%$ of patients with classic EDS and allows to refine diagnostic criteria. Hum Mutat 2012, 33: $1485-1493$

8. Greenspan DS, Hoffman GG, Lee BS: High levels of expression of full length human pro-alpha 2(V) collagen cDNA in pro-alpha 2(V)-deficient hamster cells. J Biol Chem 1989, 264:20683-20687

9. Wenstrup RJ, Florer JB, Brunskill EW, Bell SM, Chervoneva I, Birk DE: Type V collagen controls the initiation of collagen fibril assembly. J Biol Chem 2004, 279:53331-53337

10. Wenstrup RJ, Florer JB, Davidson JM, Phillips CL, Pfeiffer BJ, Menezes DW, Chervoneva I, Birk DE: Murine model of the EhlersDanlos syndrome. col5a1 haploinsufficiency disrupts collagen fibril assembly at multiple stages. J Biol Chem 2006, 281:12888-12895

11. Wenstrup RJ, Meyer RA, Lyle JS, Hoechstetter L, Rose PS, Levy HP, Francomano CA: Prevalence of aortic root dilation in the EhlersDanlos syndrome. Genet Med 2002, 4:112-117

12. McDonnell NB, Gorman BL, Mandel KW, Schurman SH, AssanahCarroll A, Mayer SA, Najjar SS, Francomano CA: Echocardiographic findings in classical and hypermobile Ehlers-Danlos syndromes. Am J Med Genet A 2006, 140:129-136

13. Atzinger CL, Meyer RA, Khoury PR, Gao Z, Tinkle BT: Crosssectional and longitudinal assessment of aortic root dilation and valvular anomalies in hypermobile and classic Ehlers-Danlos syndrome. J Pediatr 2011, 158:826-830.e1

14. Andrikopoulos K, Liu X, Keene DR, Jaenisch R, Ramirez F: Targeted mutation in the col5a2 gene reveals a regulatory role for type $\mathrm{V}$ collagen during matrix assembly. Nat Genet 1995, 9:31-36

15. Chanut-Delalande H, Bonod-Bidaud C, Cogne S, Malbouyres M, Ramirez F, Fichard A, Ruggiero F: Development of a functional skin matrix requires deposition of collagen $\mathrm{V}$ heterotrimers. Mol Cell Biol 2004, 24:6049-6057

16. Greenspan DS, Lee ST, Lee BS, Hoffman GG: Homology between alpha 2(V) and alpha 1(III) collagen promoters and evidence for negatively acting elements in the alpha 2(V) first intron and 5' flanking sequences. Gene Expr 1991, 1:29-39

17. Truter S, Di Liberto M, Inagaki Y, Ramirez F: Identification of an upstream regulatory region essential for cell type-specific transcription of the pro-alpha 2(V) collagen gene (COL5A2). J Biol Chem 1992 , 267:25389-25395 
18. Penkov D, Tanaka S, Di Rocco G, Berthelsen J, Blasi F, Ramirez F: Cooperative interactions between PBX, PREP, and HOX proteins modulate the activity of the alpha $2(\mathrm{~V})$ collagen $(\mathrm{COL} 5 \mathrm{~A} 2)$ promoter. J Biol Chem 2000, 275:16681-16689

19. Tybulewicz VL, Crawford CE, Jackson PK, Bronson RT, Mulligan RC: Neonatal lethality and lymphopenia in mice with a homozygous disruption of the c-abl proto-oncogene. Cell 1991, 65:1153-1163

20. Shalaby F, Rossant J, Yamaguchi TP, Gertsenstein M, Wu XF, Breitman ML, Schuh AC: Failure of blood-island formation and vasculogenesis in Flk-1-deficient mice. Nature 1995, 376:62-66

21. Rodriguez CI, Buchholz F, Galloway J, Sequerra R, Kasper J, Ayala R, Stewart AF, Dymecki SM: High-efficiency deleter mice show that FLPe is an alternative to Cre-loxP. Nat Genet 2000, 25:139-140

22. Xin HB, Deng KY, Rishniw M, Ji G, Kotlikoff MI: Smooth muscle expression of Cre recombinase and eGFP in transgenic mice. Physiol Genomics 2002, 10:211-215

23. Pappano WN, Steiglitz BM, Scott IC, Keene DR, Greenspan DS: Use of Bmp1/Tl11 doubly homozygous null mice and proteomics to identify and validate in vivo substrates of bone morphogenetic protein 1/tolloid-like metalloproteinases. Mol Cell Biol 2003, 23:4428-4438

24. Fisher LW, Stubbs JT 3rd, Young MF: Antisera and cDNA probes to human and certain animal model bone matrix noncollagenous proteins. Acta Orthop Scand Suppl 1995, 266:61-65
25. Vouyouka AG, Pfeiffer BJ, Liem TK, Taylor TA, Mudaliar J, Phillips CL: The role of type I collagen in aortic wall strength with a homotrimeric. J Vasc Surg 2001, 33:1263-1270

26. Birk DE, Trelstad RL: Extracellular compartments in tendon morphogenesis: collagen fibril, bundle, and macroaggregate formation. J Cell Biol 1986, 103:231-240

27. Ezura Y, Chakravarti S, Oldberg A, Chervoneva I, Birk DE: Differential expression of lumican and fibromodulin regulate collagen fibrillogenesis in developing mouse tendons. J Cell Biol 2000, 151: 779-788

28. Bentz H, Bachinger HP, Glanville R, Kuhn K: Physical evidence for the assembly of A and B chains of human placental collagen in a single triple helix. Eur J Biochem 1978, 92:563-567

29. Haralson MA, Mitchell WM, Rhodes RK, Kresina TF, Gay R, Miller EJ: Chinese hamster lung cells synthesize and confine to the cellular domain a collagen composed solely of B chains. Proc Natl Acad Sci U S A 1980, 77:5206-5210

30. Imamura Y, Steiglitz BM, Greenspan DS: Bone morphogenetic protein-1 processes the NH2-terminal propeptide, and a furin-like proprotein convertase processes the $\mathrm{COOH}$-terminal propeptide of pro-alpha1(V) collagen. J Biol Chem 1998, 273:27511-27517

31. Grahame R, Beighton P: Physical properties of the skin in the EhlersDanlos syndrome. Ann Rheum Dis 1969, 28:246-251 